\title{
Mixed integer nonlinear programming (MINLP)-based bandwidth utility function on internet pricing scheme with monitoring and marginal cost
}

\author{
Robinson Sitepu ${ }^{1}$, Fitri Maya Puspita ${ }^{2}$, Elika Kurniadi ${ }^{3}$, Yunita $^{4}$, Shintya Apriliyani ${ }^{5}$ \\ ${ }^{1,2,5}$ Department of Mathematics, Faculty of Mathematics and Natural Sciences, Sriwijaya University, Indonesia \\ ${ }^{3}$ Mathematics Study Program, Faculty of Education and Teacher Training, Sriwijaya University, Indonesia \\ ${ }^{4}$ Informatics Engineering, Faculty of Computer Science, Sriwijaya University, Indonesia
}

\begin{abstract}
Article Info
Article history:

Received Nov 22, 2017

Revised Sep 17, 2018

Accepted Oct 1, 2018

\section{Keywords:}

Marginal cost

MINLP

Monitoring cost

Pricing scheme

Utility function

ABSTRACT

The development of the internet in this era of globalization has increased fast. The need for internet becomes unlimited. Utility functions as one of measurements in internet usage, were usually associated with a level of satisfaction of users for the use of information services used. There are three internet pricing schemes used, that are flat fee, usage based and two-part tariff schemes by using one of the utility function which is Bandwidth Diminished with Increasing Bandwidth with monitoring cost and marginal cost. Internet pricing scheme will be solved by LINGO 13.0 in form of nonlinear optimization problems to get optimal solution. The optimal solution is obtained using the either usage-based pricing scheme model or two-part tariff pricing scheme model for each services offered, if the comparison is with flat-fee pricing scheme. It is the best way for provider to offer network based on usage based scheme. The results show that by applying two part tariff scheme, the providers can maximize its revenue either for homogeneous or heterogeneous consumers.
\end{abstract}

Copyright () 2019 Institute of Advanced Engineering and Science. All rights reserved.

\section{Corresponding Author:}

Fitri Maya Puspita

Department of Mathematics,

Faculty of Mathematics and Natural Sciences,

Sriwijaya University,

Jln. Raya Palembang-Prabumulih, KM 32 Inderalaya Ogan Ilir 30662 South Sumatera, Indonesia.

Email: pipitmac140201@gmail.com

\section{INTRODUCTION}

The development of the internet in this era of globalization has increased rapidly. The need for internet usage becomes unlimited due to its easiness [1] and for internet service provider companies or ISP, it is a big challenge in satisfy their customers to meet the needs of its customers by providing the best service for consumers and still pay attention to the benefits for Internet Service Provider itself. In designing the model of internet pricing scheme, there should be a match between the price given and the satisfaction obtained by consumer. The level of satisfaction canbe related to the utility function. Utility functions were usually associated with a level of satisfaction that user gets for the use of information services used specifically relating to maximize profits in achieving specific goal [2] and can be written with $U=f\left(x_{1}, x_{2}, x_{3}, \ldots, x_{n}\right)$ which means that $x_{1}, x_{2}, x_{3}, \ldots, x_{n}$ contribute the user utility. So the well-known utility function used by researchers in pricing information services are Cobb-Douglass, Quasi-Linear, Perfect Substitute and a function of bandwidth utility functions [3]-[5]. There are three internet pricing scheme used, that is flat fee, usage based and two part tariff to be applied to Internet pricing scheme by using one of the utility function which is Cobb-Douglass modified utility function to maximize benefits to the ISP [6]. 
$\mathrm{Wu}$ and Banker [6] chose three internet pricing scheme that are flat fee, usage based and two-part tariff by applying modified utility function of Cobb Douglass in order to maximize the profits by ISP. QoS (Quality of Service) is the transmission rates, error rates and other level of measurable characteristics to support the level of progress at a service provider [7]. QoS involved a collection of data transmission-quality parameters through a communication network. Basically, QoS allows to provide better services for specific requests [8]. For instance, QoS routing is to choose single reliable and dependable paths in networks, by utilizing the packet flow from source to destination [9]. To show the efficiency of ISP in service there must be an interaction between price and QoS [10]. Besides that the QoS metric also play important role in measuring the end to end user's satisfaction [11]. Based on the research discussed by [12] the optimal internet pricing scheme for homogenous and heterogeneous consumer case (High end and Low end) is obtained in utility functions of Bandwidth with flat fee scheme by ignoring the monitoring cost and marginal cost. From the analysis done by [5], [13], it is found that utility function of Bandwidth produce maximum profit for ISP with flat fee pricing scheme for homogenous and heterogeneous (High end and Low end) consumer with monitoring cost and marginal cost. Also, based on the research conducted [14] on the models application of each traffic data it is found that the use of other utility functions can result in optimal pricing scheme

In general, the marginal costs are defined as the costs adjusted to the level of production of goods which are resulting in differences of fixed costs due to the addition of the number of units produced. While the cost of monitoring is the cost incurred by the company to monitor and control the activities carried out by the agency in managing company. In fact, the marginal cost and the monitoring cost an important in consideration for internet service provider in maximizing profits. The main contribution of this paper, then is to formulate the pricing scheme based-utility function previously discussed differentially into mixed integer nonlinear programming to enable us to seek other option in solving pricing scheme with monitoring cost and the marginal cost based on bandwidth utility function for information services as the optimization problem.

\section{RESEARCH METHOD}

Steps conducted in this research are as follows:

a. Conduct data processing that includes the digilib traffic and mail traffic data, which divided into two categories, based on the use during peak hours and the use non peak hours and define the parameters used.

b. Determine the information service pricing scheme models according to bandwidth utility functions with flat fee, usage-based, dan two-part tariff pricing scheme for homogeneous and heterogeneous consumers.

1. For flat fee pricing scheme, $P_{X}=0, P_{Y}=0$ and $P$ adalah is positive.

2. For usage-based scheme, $P_{X}$ and $P_{Y}$ are positive and $P=0$.

3. For two-part tariff scheme, $P, P_{X}$ and $P_{Y}$ are positive.

c. Formulate bandwidth utility function according to flat fee, usage-based, and two-part tariff pricing schemes for homogeneous and heterogeneous consumers with paying attention to marginal and monitoring cots.

d. Apply the optimal pricing scheme of local data server of digilib and mail traffic data and solve the result by LINGO 13.0 then compare the pricing scheme models to each utility function for each consumers.

e. Conclude and obtain the best solution of information service pricing scheme.

\section{RESULTS AND ANALYSIS}

This section discusses other utility function that is also well known namely bandwidth utility function. The optimization problems are divided into two categories, which are consumer and provider problems.

a) Optimization of consumers' problem

$$
\operatorname{Max}_{X_{i}, Y_{i}, Z_{i}} U_{i\left(X_{i}, Y_{i}\right)}-P_{X} X_{i}-P_{Y} Y_{i}-P Z_{i}
$$

Subject to:

$$
\begin{aligned}
& X_{i} \leq \bar{X}_{l} Z_{i} \\
& Y_{i} \leq \bar{Y}_{l} Z_{i} \\
& U_{i\left(X_{i}, Y_{i}\right)}-P_{X} X_{i}-P_{Y} Y_{i}-P Z_{i} \geq 0 \\
& Z_{i}=0 \text { or } 1
\end{aligned}
$$


b) Optimization of providers' problem

$$
\begin{aligned}
& \operatorname{Max}_{P, P_{X}, P_{Y}} \sum_{i}\left(P_{x} X_{i}^{*}+P_{y} Y_{i}^{*}+P Z_{i}^{*}\right) \\
& \text { with }\left(X_{i}^{*}, Y_{i}^{*}, Z_{i}^{*}\right)=\operatorname{argmax} U_{i}\left(X_{i}, Y_{i}\right)-P_{x} X_{i}-P_{y} Y_{i}-P Z_{i} \\
& \text { Subject to: } \\
& X_{i} \leq \bar{X}_{l} Z_{i} \\
& Y_{i} \leq \bar{Y}_{l} Z_{i} \\
& U_{i}\left(X_{i}, Y_{i}\right)-P_{x} X_{i}-P_{y} Y_{i}-P Z_{i} \geq 0 \\
& Z_{i}=0 \text { or } 1
\end{aligned}
$$

c) Bandwidth utility function

According to [15] the Bandwidth utility function :

$$
U_{k j}=U_{0 j}+W_{j} \ln \frac{X_{k j}}{L_{m j}}
$$

The calculation of (3) is changed to:

$$
\mathrm{U}(\mathrm{X}, \mathrm{Y})=\mathrm{U}_{0}+a \ln \frac{X+1}{X_{m}+1}+b \ln \frac{Y+1}{Y_{m}+1}
$$

Table 1 and Table 2 describe the internet usage for digilib and mail data in peak and non-peak hours while Table 3 and Table 4 explain the parameter and variables used in the consumer and provider optimization problem, respectively. Table 5 and Table 6 describe to the decision variables use for consumer and provider optimization problem.

Table 1. Internet Usage Data during Peak and Non-Peak Hours for Digilib Traffic

\begin{tabular}{ccc}
\multicolumn{3}{c}{ Non-Peak Hours for Digilib Traffic } \\
\hline $\bar{X}=\bar{X}_{1}$ & $2,278.00$ & Digilib (kbps) \\
$\bar{X}_{2}$ & $1,927.64$ & 2.22 \\
$X_{m}$ & 515.44 & 1.88 \\
$\bar{Y}=\bar{Y}_{1}$ & $14,755.36$ & 0.50 \\
$\overline{\bar{Y}}_{2}$ & $4,465.03$ & 14.41 \\
$Y_{m}$ & $1,151.24$ & 4.36 \\
\end{tabular}

Table 2. Internet Usage Data during Peak and Non-Peak Hours for Mail Traffic

\begin{tabular}{ccc}
\multicolumn{3}{c}{ Non-Peak Hours for Mail Traffic } \\
\hline $\bar{X}=\bar{X}_{1}$ & $460,959.55$ & Mail $(\mathrm{kbps})$ \\
$\bar{X}_{2}$ & $180,157.62$ & 450.16 \\
$X_{m}$ & $53,958.72$ & 175.94 \\
$\bar{Y}=\bar{Y}_{1}$ & $372,947.24$ & 52.69 \\
$\overline{\bar{Y}}_{2}$ & $339,505.75$ & 364.21 \\
$Y_{m}$ & $141,906.85$ & 331.55 \\
\hline
\end{tabular}

Table 3. Parameters for Consumers' Optimization Problem

\begin{tabular}{cll} 
& & \\
\hline Symbol & & Meaning \\
\hline$P$ & $:$ & The costs incurred when following the services provided \\
$P_{x}$ & $:$ & The price provided by the service provider (ISP) during peak hours $(09.00-16.59)$. \\
$P_{y}$ & $:$ & The price provided by the service provider (ISP) during not busy hours. (17.00-08.59). \\
$U_{i}\left(X_{i}, Y_{i}\right)$ & $:$ & $\begin{array}{l}\text { The utility function from consumer } i \text { with } X_{i} \text { is the level of service usage during peak hours and } Y_{i} \text { is the level of } \\
\text { service usage during not busy hours. }\end{array}$ \\
\hline
\end{tabular}

Table 4. Parameters for Optimization Provider Problem

\begin{tabular}{ccl}
\hline Symbol & & \multicolumn{1}{c}{ Meaning } \\
\hline$X_{i} *=X_{i\left(P_{x}, P_{y}, P\right)}$ & $:$ & The level of consumer service consumption $i$ during peak hours. \\
$Y_{i}{ }^{*}=Y_{\left(P_{x}, P_{y}, P\right)}$ & $:$ & The level of consumer service consumption $i$ during not busy hours. \\
$Z_{i}^{*}=Z_{i\left(P_{x}, P_{y}, P\right)}$ & $:$ & Consumer variable $i$ to show the participation of the scheme \\
$U_{i}\left(X_{i}, Y_{i}\right)$ & $:$ & The utility function from consumer $i$ with $X_{i}$ is the level of service usage during peak hours and $Y_{i}$ is the level \\
$\bar{X}_{l}$ & $:$ & of service usage during not busy hours. \\
$\bar{Y}_{l}$ & $:$ & The highest level of consumers $i$ in using the service during peak hours.
\end{tabular}


Table 5. Decision Variable for Consumers' Optimization Problem

\begin{tabular}{cll}
\hline Symbol & & Meaning \\
\hline$X_{i}$ & $:$ & The level of consumption consumer $i$ on the peak hours. \\
$Y_{i}$ & $:$ & The level of consumption consumer $i$ on the non-peak hours. \\
$Z_{i}$ & $:$ & The decision variable which have value 1 if consumers chosen to join the program and have value 0 \\
$\bar{X}_{l}$ & $:$ & The maximum level of consumption consumer $i$ on the peak hours. \\
$\bar{Y}_{l}$ & $:$ & The maximum level of consumption consumer $i$ on the non-peak hours. \\
\hline
\end{tabular}

Table 6. Decision Variable for Provider Optimization Problem

\begin{tabular}{cll}
\hline Symbol & & Meaning \\
\hline$P$ & $:$ & The cost required to join the service program. \\
$P_{x}$ & $:$ & The price of the service specified by ISP during peak hours. \\
$P_{y}$ & $:$ & The price of the service specified by ISP during non-peak hours. \\
\hline
\end{tabular}

d) Digilib traffic data

In this section the explanations about provider optimization with three pricing scheme which applied to digilib traffic data for homogeneous consumers and heterogeneous consumers are described. The parameters value usage for will to show in the Tables 7-9.

Table 7. Parameter Values for Homogeneous Consumers for Digilib Traffic

\begin{tabular}{cccc}
\hline Parameters & Flat Fee & Usage Based & Two Part Tariff \\
\hline $\mathrm{A}$ & 5 & 5 & 5 \\
$\mathrm{~B}$ & 4 & 4 & 4 \\
$\overline{\mathrm{X}}$ & 2.22 & 2.22 & 2.22 \\
$\mathrm{X}_{\mathrm{m}}$ & 0.50 & 0.50 & 0.50 \\
$\overline{\mathrm{Y}}$ & 14.41 & 14.41 & 14.41 \\
$\mathrm{Y}_{\mathrm{m}}$ & 1.12 & 1.12 & 1.12 \\
\hline
\end{tabular}

By substituting the parameters value in Table 7, it can be model on the homogeneous consumer based on (4) equation as shown by the (5):

$$
\operatorname{Max} P x X+P y Y+P Z+(X+Y) C-U_{0}+5 \ln \frac{X+1}{X_{m}+1}+4 \ln \frac{Y+1}{Y_{m}+1}
$$

Subject to:

$$
\begin{aligned}
& X \leq 2.22 Z \\
& Y \leq 14.41 Z \\
& Z=1
\end{aligned}
$$

Table 8. Parameter Values for High End and Low End Heterogeneous Consumers for Digilib Traffic

\begin{tabular}{cccc}
\hline Parameters & Flat Fee & Usage Based & Two Part Tariff \\
\hline$a_{1}$ & 5 & 5 & 5 \\
$a_{2}$ & 4 & 4 & 4 \\
$b_{1}$ & 3 & 3 & 3 \\
$b_{2}$ & 2 & 2 & 2 \\
$\overline{\mathrm{X}}_{1}$ & 2.22 & 2.22 & 2.22 \\
$\overline{\mathrm{X}}_{2}$ & 1.88 & 1.88 & 1.88 \\
$X_{m}$ & 0.50 & 0.50 & 0.50 \\
$\overline{\mathrm{Y}}_{1}$ & 14.41 & 14.41 & 14.41 \\
$\overline{\mathrm{Y}}_{2}$ & 4.36 & 4.36 & 4.36 \\
$Y_{m}$ & 1.12 & 1.12 & 1.12 \\
\hline
\end{tabular}

Model for High end and Low end Heterogeneous consumers shown at (9). 
Max PxX $X_{1}+P y Y_{1}+P x X_{2}+P y Y_{2}+P Z+\left(X_{1}+Y_{1}\right) C+\left(X_{2}+Y_{2}\right) C-\left(\left(U_{0}+5 \ln \frac{X+1}{X_{m}+1}\right.\right.$

$\left.\left.+3 \ln \frac{Y+1}{Y_{m}+1}\right)+\left(U_{0}+4 \ln \frac{X+1}{X_{m}+1}+2 \ln \frac{Y+1}{Y_{m}+1}\right)\right)$

Subject to:

$$
\begin{aligned}
& X_{1} \leq 2.22 \mathrm{Z} \\
& \mathrm{Y}_{1} \leq 14.41 \mathrm{Z} \\
& \mathrm{X}_{2} \leq 1.88 \mathrm{Z} \\
& \mathrm{Y}_{2} \leq 4.36 \mathrm{Z} \\
& \mathrm{Z}=1
\end{aligned}
$$

Based on the Table 9 it can be model shown (15) as following.

$$
\begin{aligned}
& \text { Max PxX } X_{1}+P y Y_{1}+P x X_{2}+P y Y_{2}+P Z+\left(X_{1}+Y_{1}\right) C+\left(X_{2}+Y_{2}\right) C-\left(U_{0}+5 \ln \right. \\
& \left.\left.\frac{X+1}{X_{m}+1}+4 \ln \frac{Y+1}{Y_{m}+1}\right)+\left(U_{0}+5 \ln \frac{X+1}{X_{m}+1}+4 \ln \frac{Y+1}{Y_{m}+1}\right)\right)
\end{aligned}
$$

Subject to :

$$
\begin{aligned}
& X \leq 2.22 \mathrm{Z} \\
& Y \leq 14.41 \mathrm{Z} \\
& \mathrm{X}_{2} \leq 1.88 \mathrm{Z} \\
& \mathrm{Y}_{2} \leq 4.36 \mathrm{Z} \\
& \mathrm{Z}=1
\end{aligned}
$$

Table 9. Parameter Values for High Demand and Low Demand Heterogeneous Consumers of Digilib Traffic

\begin{tabular}{cccc}
\hline Parameters & Flat Fee & Usage Based & Two Part Tariff \\
\hline$a_{1}$ & 5 & 5 & 5 \\
$a_{2}$ & 5 & 5 & 5 \\
$b_{1}$ & 4 & 4 & 4 \\
$b_{2}$ & 4 & 4 & 4 \\
$\bar{X}_{1}$ & 2.22 & 2.22 & 2.22 \\
$\overline{\mathrm{X}}_{2}$ & 1.88 & 1.88 & 1.88 \\
$X_{m}$ & 0.50 & 0.50 & 0.50 \\
$\overline{\mathrm{Y}}_{1}$ & 14.41 & 14.41 & 14.41 \\
$\overline{\mathrm{Y}}_{2}$ & 4.36 & 4.36 & 4.36 \\
$\boldsymbol{Y}_{\boldsymbol{m}}$ & 1.12 & 1.12 & 1.12 \\
\hline
\end{tabular}

e) Mail traffic data

In this section we will to explain about optimization of provider with three pricing scheme which applied to Mail traffic data for homogeneous consumers and heterogeneous consumers. The parameter value usage is shown in Table 10 Table 11 and Table 12.

Table 10. Parameter Values for Homogeneous Consumers for Mail Traffic

\begin{tabular}{cccc}
\hline Parameters & Flat Fee & Usage Based & Two Part Tariff \\
\hline $\mathrm{A}$ & 5 & 5 & 5 \\
$\mathrm{~B}$ & 4 & 4 & 4 \\
$\overline{\mathrm{X}}$ & 450.16 & 450.16 & 450.16 \\
$\boldsymbol{X}_{\boldsymbol{m}}$ & 52.69 & 52.69 & 52.69 \\
$\overline{\mathrm{Y}}$ & 364.21 & 364.21 & 364.21 \\
$\boldsymbol{Y}_{\boldsymbol{m}}$ & 138.58 & 138.58 & 138.58 \\
\hline
\end{tabular}


By substituting the parameters value in Table 10, it can be modelled on the homogeneous consumer based on the equation of Cobb-Douglas utility function as shown by the (21):

$$
\operatorname{Max} P x X+P y Y+P Z+(X+Y) C-U_{0}+5 \ln \frac{X+1}{X_{m}+1}+4 \ln \frac{Y+1}{Y_{m}+1}
$$

Subject to:

$$
\begin{aligned}
& X \leq 450.16 Z \\
& Y \leq 364.21 Z \\
& Z=1
\end{aligned}
$$

Table 11. Parameter Values for High End and Low End Heterogeneous Consumers of Mail Traffic

\begin{tabular}{cccc}
\hline Parameters & Flat Fee & Usage Based & Two Part Tariff \\
\hline$a_{1}$ & 5 & 5 & 5 \\
$a_{2}$ & 4 & 4 & 4 \\
$b_{1}$ & 3 & 3 & 3 \\
$b_{2}$ & 2 & 2 & 2 \\
$\overline{\mathrm{X}}_{1}$ & 450.16 & 450.16 & 450.16 \\
$\overline{\mathrm{X}}_{2}$ & 175.94 & 175.94 & 175.94 \\
$X_{m}$ & 52.69 & 52.69 & 52.69 \\
$\overline{\mathrm{Y}}_{1}$ & 364.21 & 364.21 & 364.21 \\
$\overline{\bar{Y}}_{2}$ & 331.55 & 331.55 & 331.55 \\
$Y_{m}$ & 138.58 & 138.58 & 138.58 \\
\hline
\end{tabular}

Model for High end and Low end Heterogeneous consumers by using Table 11, is shown in (25).

$$
\begin{aligned}
& \operatorname{Max} P x X_{1}+P y Y_{1}+P x X_{2}+P y Y_{2}+P Z+\left(X_{1}+Y_{1}\right) C+\left(X_{2}+Y_{2}\right) C-\left(\left(U_{0}+5 \ln \frac{X+1}{X_{m}+1}\right.\right. \\
& \left.\left.+3 \ln \frac{Y+1}{Y_{m}+1}\right)+\left(U_{0}+4 \ln \frac{X+1}{X_{m}+1}+2 \ln \frac{Y+1}{Y_{m}+1}\right)\right)
\end{aligned}
$$

Subject to:

$$
\begin{aligned}
& X_{1} \leq 450.16 Z \\
& Y_{1} \leq 364.21 Z \\
& X_{2} \leq 175.94 Z \\
& Y_{2} \leq 331.55 Z \\
& Z=1
\end{aligned}
$$

Based on the Table 12, it can be modelled like stated in (32).

$$
\begin{aligned}
& \operatorname{Max} P x X_{1}+P y Y_{1}+P x X_{2}+P y Y_{2}+P Z+\left(X_{1}+Y_{1}\right) C+\left(X_{2}+Y_{2}\right) C-\left(\left(U_{0}+5 \ln \frac{X+1}{X_{m}+1}+4\right.\right. \\
& \left.\left.\ln \frac{Y+1}{Y_{m}+1}\right)+\left(U_{0}+5 \ln \frac{X+1}{X_{m}+1}+4 \ln \frac{Y+1}{Y_{m}+1}\right)\right)
\end{aligned}
$$

Subject to:

$$
\begin{aligned}
& X_{1} \leq 450.16 Z \\
& Y_{1} \leq 364.21 Z \\
& X_{2} \leq 175.94 Z
\end{aligned}
$$


$Y_{2} \leq 331.55 Z$

$$
Z=1
$$

Table 13 to Table 18 explain solutions by using LINGO 13.0 for digilib traffic data and mail traffic data. As Table 19 explain the recapitulation of result conducting by using LINGO 13.0, it can be seen that for highest revenue obtained by the provider if they offer two part tariff pricing scheme, for high end and low end user for each traffic data in network. The two-part tariff system can be considered a best option for provider to be promoted due to the subscription fee and usage based scheme that allow provider to maintain its network.

Table 12. Parameter Values for High Demand and Low Demand Heterogeneous Consumers for Mail Traffic

\begin{tabular}{cccc}
\hline Parameters & Flat Fee & Usage Based & Two Part Tariff \\
\hline $\mathrm{a}_{1}$ & 5 & 5 & 5 \\
$\mathrm{a}_{2}$ & 5 & 5 & 5 \\
$\mathrm{~b}_{1}$ & 4 & 4 & 4 \\
$\mathrm{~b}_{2}$ & 4 & 4 & 4 \\
$\overline{\mathrm{X}}_{1}$ & 450.16 & 450.16 & 450.16 \\
$\overline{\mathrm{X}}_{2}$ & 175.94 & 175.94 & 175.94 \\
$\mathrm{X}_{\mathrm{m}}$ & 52.69 & 52.69 & 52.69 \\
$\overline{\mathrm{Y}}_{1}$ & 364.21 & 364.21 & 364.21 \\
$\overline{\mathrm{Y}}_{2}$ & 331.55 & 331.55 & 331.55 \\
$\mathrm{Y}_{\mathrm{m}}$ & 138.58 & 138.58 & 138.58 \\
\hline
\end{tabular}

Table 13. The Solution for Digilib Traffic for

Homogeneous Consumer By LINGO 13.0

\begin{tabular}{lccc}
\hline Solver Status & Flat Fee & Usage Based & Two part tariff \\
\hline $\begin{array}{l}\text { Model class } \\
\text { State }\end{array}$ & $\begin{array}{c}\text { NLP } \\
\text { Local } \\
\text { optimal }\end{array}$ & $\begin{array}{c}\text { NLP } \\
\text { Local optimal }\end{array}$ & $\begin{array}{c}\text { NLP } \\
\text { Local optimal }\end{array}$ \\
Objective & 159.51 & 482.11 & 514.31 \\
Iterations & 30 & 32 & 24 \\
GMU(K) & 21 & 22 & 21 \\
\hline
\end{tabular}

Table 15. The Solution for Digilib Traffic for High Demand and Low Demand Heterogeneous Consumer by LINGO 13.0

\begin{tabular}{lccc}
\hline Solver Status & Flat Fee & Usage Based & Two part tariff \\
\hline Model class & NLP & NLP & NLP \\
State & Local & Local optimal & Local optimal \\
& optimal & & \\
Objective & 209.91 & 573.51 & 583.51 \\
Iterations & 35 & 20 & 20 \\
GMU(K) & 23 & 24 & 24 \\
\hline
\end{tabular}

Table 17. The Solution for Mail Traffic for High End and Low End Heteregeneous Consumer by LINGO 13.0

\begin{tabular}{lccc}
\hline & \multicolumn{3}{c}{ Pricing Scheme } \\
Solver Status & Flat Fee & Usage Based & Two part tariff \\
\hline Model class & NLP & NLP & NLP \\
State & Local & Local optimal & Local optimal \\
Objective & optimal & $35,686.4$ & $35,696.4$ \\
Iterations & 13,148 & 18 & 38 \\
GMU(K) & 15 & 24 & 24 \\
\hline
\end{tabular}

Table 14. The Solution for Traffic for High End and Low End Heterogeneous Consumer by LINGO 13.0

\begin{tabular}{lccc}
\hline Solver Status & Flat Fee & Usage Based & Two part tariff \\
\hline Model class & NLP & NLP & NLP \\
State & Local & Local optimal & Local optimal \\
& optimal & & \\
Objective & 217.1 & 580.66 & 590.66 \\
Iterations & 35 & 38 & 38 \\
GMU(K) & 23 & 24 & 24 \\
\hline
\end{tabular}

Table 16. The Solution for Mail Traffic for Homogeneous Consumer by LINGO 13.0

\begin{tabular}{lccc}
\hline & \multicolumn{3}{c}{ Pricing Scheme } \\
Solver Status & Flat Fee & Usage Based & Two part tariff \\
\hline Model class & NLP & NLP & NLP \\
State & Local & Local optimal & Local optimal \\
& optimal & & \\
Objective & $8,099.54$ & $24,376.9$ & $28,888.5$ \\
Iterations & 13 & 15 & 15 \\
GMU(K) & 21 & 22 & 21 \\
\hline
\end{tabular}

Table 18. The Solve Mail Traffic for High Demand and Low Demand Heterogeneous Consumer by LINGO 13.0

\begin{tabular}{lccc}
\hline & \multicolumn{3}{c}{ Pricing Scheme } \\
Solver Status & Flat Fee & Usage Based & Two part tariff \\
\hline Model class & NLP & NLP & NLP \\
& Local & Local optimal & Local optimal \\
State & optimal & & \\
& $13,125.3$ & $35,663.7$ & $35,673.7$ \\
Objective & 15 & 18 & 18 \\
Iterations & 23 & 24 & 24 \\
GMU(K) & & &
\end{tabular}


Table 19. Recapitulation of Digilib Traffic Data

\begin{tabular}{|c|c|c|c|c|}
\hline Data & Type of Pricing & Consumers & & Income \\
\hline \multirow{9}{*}{ Digilib } & \multirow{3}{*}{ flat-fee } & Homogeneous & 159.5130 & \multirow{3}{*}{$1,155.939$} \\
\hline & & Heterogeneous High end \& Low end & 482.1130 & \\
\hline & & Heterogeneous High demand \& Low demand & 514.3130 & \\
\hline & \multirow{4}{*}{ Usage based } & Homogeneous & 217.0590 & \multirow{3}{*}{$1,388.377$} \\
\hline & & Heterogeneous High end \& Low end & 580.6590 & \\
\hline & & Heterogeneous High demand \& Low demand & 590.6590 & \\
\hline & & Homogeneous & 209.9082 & \multirow{3}{*}{$1,366.9246$} \\
\hline & \multirow[t]{2}{*}{ Two-part Tariff } & Heterogeneous High end \& Low end & 573.5082 & \\
\hline & & Heterogeneous High demand \& Low demand & 583.5082 & \\
\hline
\end{tabular}

\section{CONCLUSION}

Based on the optimization result of the internet pricing scheme by considering marginal and monitoring cost of Bandwidth utility function, the optimal solution is obtained using the either usage-based pricing scheme model or two-part tariff pricing scheme model for each services offered, if we compared with flat-fee pricing scheme. It is the best way for provider to offer network on usage based pricing scheme.

\section{ACKNOWLEDGMENTS}

The research leading to this study was financially supported by Sriwijaya University for support through Hibah PNBP Unggulan Kompetitif Universitas Sriwijaya Tahun 2017.

\section{REFERENCES}

[1] Tjahjanto, B. Sitohang, and S.K. Wiryono, "Simulation and Implementation Model of Productivity Measurement Internet Bandwidth Usage," TELKOMNIKA Telecommunication Computing Electronics and Control, Vol. 13 issue 3, pp. 1069-1078, 2015.

[2] Curescu, C., "Utility-based Optimisation of Resource Allocation for Wireless Networks, in Department of Computer and Information Science", Linköpings universitet: Linköping. p. 178, 2005.

[3] Yang, W., "Pricing Network Resources in Differentiated Service Networks," in School of electrical and Computer Engineering, Phd Thesis. Georgia Institute of Technology. p. 1-111, 2004.

[4] Yang, W., H.L. Owen, and D.M. Blough. "Determining Differentiated Services Network Pricing Through Auctions," in Networking-ICN 2005, 4th International Conference on Networking April 2005 Proceedings, Part I. Reunion Island, France, : Springer-Verlag Berlin Heidelberg, 2005.

[5] Sitepu, R., Puspita, F. M., Pratiwi, A. N., and Novyasti, I. P., "Utility function-based pricing strategies in maximizing the information service provider's revenue with marginal and monitoring Costs," International Journal of Electrical and Computer Engineering (IJECE), Vol. 7 No.2, pp. 877-887, 2017.

[6] Wu, S.-y. and R.D. Banker, "Best Pricing Strategy for Information Services," Journal of the Association for Information Systems, Vol. 11 Issue 6, pp. 339-366, 2010.

[7] Yang, W., H. Owen, and D.M. Blough. "A Comparison of Auction and Flat Pricing for Differentiated Service Networks," in Proceedings of the IEEE International Conference on Communications. 2004.

[8] Bandung, Y. and I. Sumardi, "A Methodology for Characterizing Real-Time Multimedia Quality of Service in Limited Bandwidth Network," TELKOMNIKA Telecommunication Computing Electronics and Control, Volume 14 issue 4: pp. 1534-1544, 2016.

[9] Satria, M.H., J.b. Yunus, and E. Supriyanto, "802.11s QoS Routing for Telemedicine Service," International Journal of Electrical and Computer Engineering (IJECE), Volume 4 Issue 2: pp. 265-277, 2014.

[10] Barth, D., Deschinkel, K., Diallo, M., and Echabbi, L., "Pricing, QoS and Utility models for the Internet," 2004, Rapport de recherche interne \# 2004/60, Laboratoire Prism.

[11] Panimozhi, K. and G. Mahadevan, "QoS Framework for a Multi-stack based Heterogeneous Wireless Sensor Network," International Journal of Electrical and Computer Engineering (IJECE), Volume 7 Issue 5: pp. 2713$2720,2017$.

[12] Indrawati, Irmeilyana, Puspita, F. M., and Lestari, M. P., "Cobb-Douglass Utility Function in Optimizing the Internet Pricing Scheme Model," TELKOMNIKA Telecommunication Computing Electronics and Control, Volume 12 Issue 1, pp 227-240, 2014.

[13] Sitepu, R., F.M. Puspita, and S. Apriliyani, "Utility Function-Based Mixed Integer Nonlinear Programming (MINLP) Problem Model of Information Service Pricing Schemes," in IEEE-4th International Conference on Data and Software Engineering, Palembang, Indonesia. 2017: Palembang.

[14] Puspita, F.M. and M. Oktaryna, "Improved Bundle Pricing Model On Wireless Internet Pricing Scheme In Serving Multiple Qos Network Based On Quasi-Linear Utility Function," in International Conference on Electrical and Computer Engineering, IEEE Xplore, Sriwjaya University, Palembang. 2017: Sriwjaya University.

[15] Hutchinson, E., Economics. 2011. 


\section{BIOGRAPHIES OF AUTHORS}

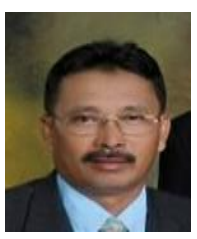

Robinson Sitepu received his Bachelor of Science in Statistics from Padjajaran University, Western Java, Indonesia. Then he received his M.Si in Mathematics from University of North Sumatera. He has been a Mathematics Department member at Faculty of mathematics and Natural Sciences Sriwijaya University South Sumatera Indonesia since 1985. His research interests include operation research and its applications and statistics.

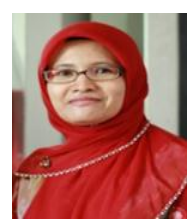

Fitri Maya Puspita received her S.Si degree in Mathematics from Sriwijaya University, South Sumatera, Indonesia in 1997. Then she received her M.Sc. in Mathematics from Curtin University of Technology (CUT) Western Australia in 2004. She received her Ph.D. in Science and Technology in 2015 from Universiti Sains Islam Malaysia. She has been a Mathematics Department member at Faculty of mathematics and Natural Sciences Sriwijaya University South Sumatera Indonesia since 1998. Her research interests include optimization and its applications such as vehicle routing problems and QoS pricing and charging in third generation internet.

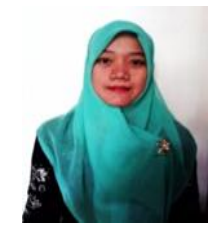

Elika received her S.Pd degree in Mathematics Education from Sriwijaya University, South Sumatera, Indonesia in 2010. Then she also received her M.Pd in Mathematics Education from Sriwijaya University, South Sumatera, Indonesia in 2013. She has been a Mathematics Education Study Program member at Faculty of Education and Teacher Training Sriwijaya University South Sumatera Indonesia since 2014. Her research interests include mathematics education and its applications especially in realistic mathematics.

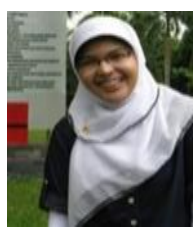

Yunita received her S.Si degree in Mathematics from Sriwijaya University, South Sumatera, Indonesia in 2006. Then she received her M.Cs in Mathematics from Gadjah Mata University, Yogyakarta in 2012. She has been an Informatics Engineering Department member at Faculty of Computer Science, Sriwijaya University South Sumatera Indonesia since 2015. Her research interests include artificial intelligence and its application.

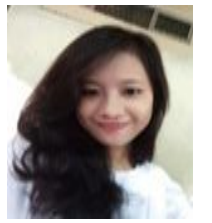

Shintya Apriliyani is currently is an undergraduate student at Mathematics Department, Faculty of Mathematics and Natural Sciences, Sriwijaya University. She is currently on final stage of her thesis submission. Her topic interest includes Optimization and its application on pricing of information service with marginal and monitoring cost. 